\title{
Descarte de córneas por sorologia positiva do doador no Banco de Olhos do Hospital São Paulo: dois anos de estudo
}

\author{
Discarded corneas due to positive donor's serologic test in the \\ Hospital São Paulo Eye Bank: a two-year study
}

\author{
Marco Túlio Chater Viegas ${ }^{1}$ \\ Lucas Calmon Pessanha ${ }^{2}$ \\ Elcio Hideo Sato ${ }^{3}$ \\ Flávio Eduardo Hirai ${ }^{4}$ \\ Consuelo Bueno Diniz Adán ${ }^{5}$
}

Trabalho realizado no Departamento de Oftalmologia da Universidade Federal de São Paulo - UNIFESP - São Paulo (SP) - Brasil.

${ }^{1}$ Estagiário do Setor de Doenças Externas Oculares e Córnea do Departamento de Oftalmologia, Instituto da Visão, Universidade Federal de São Paulo - UNIFESP - São Paulo (SP) - Brasil.

${ }^{2}$ Estagiário do Setor de Doenças Externas Oculares e Córnea do Departamento de Oftalmologia, Instituto da Visão da UNIFESP - São Paulo (SP) - Brasil.

${ }^{3}$ Doutor em Medicina, Colaborador do Setor de Doenças Externas Oculares e Córnea e Diretor médico adjunto do Banco de Olhos do Hospital São Paulo do Departamento de Oftalmologia, Instituto da Visão da UNIFESP - São Paulo (SP) - Brasil.

${ }^{4}$ Mestre em Saúde Pública, Médico Assistente e Pósgraduando do Departamento de Oftalmologia, Instituto da Visão da UNIFESP - São Paulo (SP) - Brasil

${ }_{5}^{5}$ Doutora em Medicina, colaboradora do Setor de Doenças Externas Oculares e Córnea e Diretora médica do Banco de Olhos do Hospital São Paulo do Departamento de Oftalmologia, Instituto da Visão da UNIFESP - São Paulo (SP) - Brasil.

Endereço para correspondência: Marco Túlio Chater Viegas. Rua Dr. Diogo de Faria, 671 - Apto. 71 - São Paulo (SP) CEP 04037-002

E-mail: mt.viegas@bol.com.br

Recebido para publicação em 11.07.2008

Última versão recebida em 09.12.2008

Aprovação em 22.12.2008

\section{RESUMO}

Objetivos: Investigar descarte de córneas por sorologia positiva de doadores no Banco de Olhos do Hospital São Paulo (BOHSP) durante período de dois anos. Métodos: Revisão retrospectiva de prontuários de doadores de córneas do BOHSP entre janeiro de 2006 a dezembro de 2007. Correlações de dados como sorologias dos doadores (Hepatites B, C e HIV), procedência, sexo e faixa etária dos mesmos foram testados. Resultados: Das 902 córneas processadas no BOHSP, 12,9\% (116) apresentaram resultado positivo para hepatite $\mathrm{B}$, hepatite $\mathrm{C}$ ou $\mathrm{HIV}$ em seus doadores; $20,5 \%$ (185) apresentaram testes sorológicos inconclusivos perfazendo uma porcentagem de $33,4 \%$ (301) de córneas descartadas no período estudado devido a resultado positivo ou inconclusivo da sorologia dos doadores. Conclusão: $\mathrm{O}$ estudo confirma a validade e a importância da realização de testes sorológicos para prevenção de doenças que poderiam ser transmitidas aos eventuais receptores de córneas. Entretanto, testes mais eficazes são necessários para diminuir o número de casos de sorologias inconclusivas, visando diminuir o descarte de córneas que poderiam ser utilizadas.

Descritores: Banco de olhos; Infecções oculares virais; Córnea/microbiologia; Transplante de córnea; Sorologia; Hepatite C/diagnóstico; Doadores de tecidos

\section{INTRODUÇÃO}

Apesar de raro, o potencial para transmissão de doenças por enxerto de órgãos e tecidos existe ${ }^{(1)}$. Mesmo tecidos avasculares como a córnea, já demonstraram ser meios de contaminação e transmissão ${ }^{(1)}$. Há relatos de infecções causadas por bactérias, fungos, vírus e mesmo príons adquiridos por transplante de córnea ${ }^{(1-6)}$. A legislação brasileira não permite o uso de tecidos para transplante, cujo doador apresente sorologia positiva para hepatite $\mathrm{B}$, hepatite $\mathrm{C}$ ou $\mathrm{HIV}^{(7)}$.

É da responsabilidade dos Bancos de Olhos captar, processar, armazenar e distribuir tecidos oculares para fins terapêuticos e assim, essas instituições têm como premissa garantir a segurança do receptor do tecido ${ }^{(8)}$.

A literatura nacional mostra-se escassa sob este aspecto o que motivou a realização do presente estudo.

O objetivo deste trabalho foi determinar o percentual do descarte de córneas processadas pelo Banco de Olhos do Hospital São Paulo, por sorologias positivas no período de dois anos. 


\section{MÉTODOS}

O presente estudo foi submetido ao Comitê de Ética e Pesquisa da Universidade Federal de São Paulo e aprovado sob o número 0617/08.

Estudo retrospectivo com revisão de prontuários dos doadores de córneas processadas pelo Banco de Olhos do Hospital São Paulo (BOHSP), durante 24 meses (janeiro de 2006 a dezembro de 2007). As córneas foram procedentes de doadores do próprio Hospital São Paulo, de outros hospitais ou de pacientes cujos óbitos ocorreram em suas residências (domicílios).

Antes de efetuar a captação dos tecidos oculares, as equipes realizaram entrevista com familiares, análise do prontuário e exame do corpo do doador, na tentativa de selecioná-los quanto à ausência de doenças como hepatites virais, AIDS, uso de drogas endovenosas ou outras doenças que contraindicariam a captação. A seguir, obteve-se amostra sanguínea do doador, já previamente selecionado pela história clínica, para a realização de sorologias para hepatites B, C e HIV (HBsAg, Anti Hbc, Anti HCV, anti-HIV1 e anti-HIV2). Amostras foram provenientes de punções venosas (subclávia, femoral, jugular) ou intra-cardíaca, conforme facilidade de acesso para obtenção das mesmas. Sangue foi coletado em tubo seco, armazenado sob refrigeração $\left(2^{\circ} \mathrm{C}\right.$ a $\left.8^{\circ} \mathrm{C}\right)$ e encaminhado ao Hemocentro onde sorologias dos tecidos foram processadas.

Pesquisa de anticorpos anti-HIV 1 e 2 foi realizada por técnica imunoenzimática (Genescreen ${ }^{\circledR}$ Ultra HIV Ag- Ab, Bio-Rad, EUA). Para hepatite C, pesquisa de anticorpos anti$\mathrm{HCV}$ foi realizada pelo teste ELISA HCV $3.0 \mathrm{ORTHO}^{\circledR} \mathrm{com}$ melhoria SAVe ${ }^{\circledR}$ (ORTHO Clinical Diagnostics, EUA), considerado um teste de terceira geração. Para hepatite B foi realizada pesquisa de anticorpos dirigidos contra antígeno do núcleo do vírus por técnica imunoenzimática Monolisa antiHbc PLUS $^{\circledR}$ (Bio-Rad, EUA) e pesquisa de antígenos de superfície do vírus por técnica imunoenzimática (Monolisa ${ }^{\circledR}$ HbsAg Ultra Bio-Rad, EUA). Os mesmos testes foram utilizados para verificação de sorologias no Hospital Santa Marcelina, que é responsável pelo envio de grande parte das córneas captadas para serem distribuídas pelo Banco de Olhos do Hospital São Paulo - BOHSP.

Foram coletados dados como hospital de origem, idade e sexo dos doadores. Os resultados de cada sorologia foram agrupados em três categorias: positiva, negativa e inconclusiva, ou seja, foi impossível uma determinação de sorologia confiável devido às amostras de sangue insuficientes ou alteradas. Para as análises estatísticas utilizou-se o teste $\mathrm{t}$ de Student para variáveis contínuas e qui-quadrado ou teste exato de Fisher para variáveis categóricas. Testes derivados do teste de Wilcoxon foram aplicados para testar a presença de tendências em variáveis ordenadas (idade em categorias). Para análise estatística foi utilizado o programa Stata v.10 (College Park, Texas, EUA).

\section{RESULTADOS}

No período em estudo (2006 e 2007) foram processadas 902 córneas no BOHSP.

Quanto à faixa etária, a média de idade foi de 57,2 +/- 18,2 anos. O doador mais jovem foi de 2 anos e o mais idoso de 102 anos. Tabela 1 mostra a distribuição dos doadores conforme grupo etário, sendo que a maior proporção de doadores estava na faixa acima de 70 anos $(23,4 \%)$.

Quanto ao sexo verificou-se que 60,3\% (544) das córneas processadas eram provenientes de doadores do sexo masculino.

Quanto à origem de todos os tecidos, verificou-se que $50,1 \%$ (452) eram provenientes do Hospital Santa Marcelina, 23,9\% (216) do próprio Hospital São Paulo e 25,9\% (234) de outros locais.

Das 902 córneas processadas, 12,9\% (116) foram descartadas por apresentarem algum de seus resultados positivo; 20,5\% (185) apresentaram algum de seus resultados inconclusivo sendo também descartadas, perfazendo assim um total de descarte de 33,4\% (301) das córneas processadas no período estudado.

Ao se analisar o resultado das sorologias das córneas processadas no BOHSP, verificou-se que para hepatite B $10,4 \%$ (94) foram positivas e 19,8\% (179) foram inconclusivas; para hepatite $\mathrm{C} 2,9 \%$ (26) foram positivas e $16,9 \%$ (153) foram inconclusivas; já para HIV 1,0\% (09) tiveram resultado positivo e $17,7 \%$ (160) foram inconclusivas (Tabela 2).

Não houve diferença quanto ao sexo e idade ao compararmos sorologias positivas com negativas para hepatites $\mathrm{B}$ e C e HIV, desconsiderando os resultados inconclusivos. Quanto à origem, observamos uma maior proporção de sorologias positivas para hepatite B provenientes do Hospital São Paulo $(21,2 \%)$ do que outros hospitais $(9,8 \%)(\mathrm{p}<0,001)$ (Tabela 3$)$. Uma maior proporção de doadores com sorologia positiva (6,2\% vs. $2,4 \%$ ) para hepatite C também foi observada no HSP $(\mathrm{p}=0,014)$. (Tabela 4). Não houve diferença estatisticamente significativa entre sorologias positivas e negativas para HIV quanto à origem da córnea (p>1,000) (Tabela 5).

Considerando a faixa etária e sorologias positivas, não houve uma relação estatisticamente significativa entre esses dois fatores (HIV, $\mathrm{p}=0,72$; hepatite $\mathrm{B} \mathrm{p}=0,37$; hepatite $\mathrm{C}$ $\mathrm{p}=0,19$, para o teste exato de Fisher) (Figura 1).

\begin{tabular}{|lcrr|}
\hline \multicolumn{4}{|c}{ Tabela 1. Distribuição das córneas conforme idade do doador } \\
\hline Idade & Frequência & Porcentagem & Cumulativo \\
até 40 anos & 147 & $16,30 \%$ & $16,30 \%$ \\
41 a 50 & 130 & $14,41 \%$ & $30,71 \%$ \\
51 a 60 & 204 & $22,62 \%$ & $53,33 \%$ \\
61 a 70 & 210 & $23,28 \%$ & $76,61 \%$ \\
acima de 70 & 211 & $23,39 \%$ & $100,00 \%$ \\
Total & 902 & $100,00 \%$ & \\
Fonte: Banco de Olhos HSP - Revisão de prontuários de doadores de córnea \\
entre os meses de janeiro de 2006 e dezembro de 2007 \\
\hline
\end{tabular}




\begin{tabular}{|lcccc|}
\hline \multicolumn{4}{|c|}{ Tabela 2. Distribuição das córneas segundo sorologia do doador } \\
Teste & Sorologia positiva (\%) & Sorologia negativa (\%) & Sorologia indeterminada (\%) & Total \\
HIV & $9(1,00)$ & $733(81,3)$ & $160(17,7)$ & $179(19,9)$ \\
Hepatite B & $94(10,40)$ & $629(69,7)$ & $153(16,9)$ & $902(100,0)$ \\
Hepatite C & $26(2,90)$ & $723(80,2)$ & $(100,0)$ \\
Fonte: Banco de Olhos HSP - Revisão de prontuários de doadores de córnea entre os meses de janeiro de 2006 e dezembro de 2007 & $902(100,0)$ \\
\hline
\end{tabular}

\begin{tabular}{|c|c|c|c|}
\hline Origem* & $\begin{array}{c}\text { Sorologia } \\
\text { positiva (\%) }\end{array}$ & $\begin{array}{c}\text { Sorologia } \\
\text { negativa (\%) }\end{array}$ & Total (\%) \\
\hline Hospital São Paulo & $43(21,2)$ & $160(78,8)$ & $203(100,0)$ \\
\hline Outros & $51(9,8)$ & $469(90,2)$ & $520(100,0)$ \\
\hline Total & $94(13,0)$ & $629(87,0)$ & $723(100,0)$ \\
\hline
\end{tabular}

Tabela 4. Distribuição das córneas conforme origem considerando apenas sorologias de doadores positivas e negativas para hepatite C

\begin{tabular}{lccc}
\hline Origem* & $\begin{array}{c}\text { Sorologia } \\
\text { positiva (\%) }\end{array}$ & $\begin{array}{c}\text { Sorologia } \\
\text { negativa (\%) }\end{array}$ & Total (\%) \\
Hospital São Paulo & $13(6,2)$ & $196(93,8)$ & $209(100,0)$ \\
Outros & $13(2,4)$ & $527(97,6)$ & $540(100,0)$ \\
Total & $26(3,5)$ & $723(96,5)$ & $749(100,0)$ \\
* $=p=0,014$ & \\
$\begin{array}{l}\text { Fonte: Banco de Olhos HSP - Revisão de prontuários de doadores de córnea } \\
\text { entre os meses de janeiro de 2006 e dezembro de 2007 }\end{array}$ \\
\hline
\end{tabular}

Tabela 5. Distribuição das córneas conforme origem considerando apenas sorologias de doadores positivas e negativas para HIV

\begin{tabular}{lccr} 
Origem* & $\begin{array}{c}\text { Sorologia } \\
\text { positiva (\%) }\end{array}$ & $\begin{array}{c}\text { Sorologia } \\
\text { negativa (\%) }\end{array}$ & Total (\%) \\
Hospital São Paulo & $2(0,9)$ & $208(99,1)$ & $210(100,0)$ \\
Outros & $7(1,3)$ & $525(98,7)$ & $532(100,0)$ \\
Total & $9(1,2)$ & $723(98,8)$ & $742(100,0)$ \\
$\begin{array}{l}\text { Fonte: Banco de Olhos HSP - Revisão de prontuários de doadores de córnea } \\
\text { entre os meses de janeiro de 2006 e dezembro de } 2007\end{array}$ \\
\hline
\end{tabular}

\section{DISCUSSÃO}

Em relação à faixa etária, encontrou-se que a média de idade dos doadores foi de 57,2 anos, seguindo dados já publicados previamente por nosso serviço, cuja média de faixa etária foi de $56,8 \operatorname{anos}^{(9)}$. Já, alguns autores ${ }^{(10)}$ verificaram que a idade média de doadores, na série por eles descrita, encontrava-se entre 60 e 69 anos. Outros autores ${ }^{(11)}$ também verificaram que a faixa etária dos doadores encontrava-se acima de 60 anos. A diferença entre os achados em nosso trabalho e os da literatura poderia ser explicada pela expectativa de vida das diferentes populações.

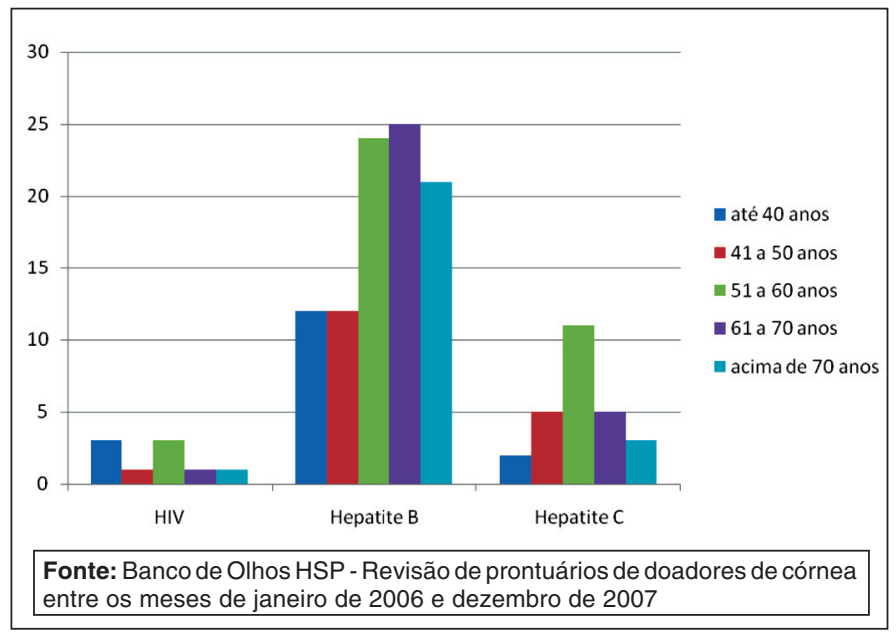

Figura 1 - Porcentagem das sorologias positivas (HIV, hepatite B e hepatite $\mathrm{C}$ ) dos doadores de córnea e suas respectivas faixas etárias

Quanto à análise da variável sexo, encontramos que 60,3\% das córneas processadas eram provenientes de doadores do sexo masculino, o que também foi observado por outros autores $^{(12)}$. Em levantamento anterior no nosso serviço, verificouse que $56,8 \%$ dos tecidos eram provenientes de doadores masculinos ${ }^{(9)}$. A preponderância de doadores homens, já citada em outros trabalhos, poderia ser explicada pelo maior número de óbitos entre a população masculina, principalmente secundários a traumatismos e doenças cardiovasculares ${ }^{(13-14)}$.

Cento e oitenta e cinco (185) córneas, correspondendo a 20,5\% das córneas processadas, apresentaram sorologias inconclusivas para hepatites B, C ou HIV. Números estes, considerados equivalentes, quando comparados aos de outras séries, cujos índices variam em torno de $24 \%^{(10)}$. Os testes com sorologias inconclusivas são repetidos para a confirmação real do resultado.

Do total de córneas processadas no período estudado, 116 $(12,9 \%)$ não foram disponibilizadas para transplantes por apresentarem algum dos testes positivos: 94 delas $(10,4 \%)$ eram positivas para hepatite $\mathrm{B}, 26(2,9 \%)$ para hepatite $\mathrm{C}$ e 9 $(1,0 \%)$ para HIV. Em levantamento anterior em nosso serviço, Sousa et al. verificaram que a soropositividade para HIV, hepatite $\mathrm{B}$ e $\mathrm{C}$ variou de $21,1 \%$ a $25,3 \%{ }^{(11)}$. Um período mais prolongado entre o óbito e a punção venosa, processo que ocorre durante a captação, poderia ser o responsável por alterações no soro como degradação tecidual, hemólise, alteração do $\mathrm{pH}$, ocasionando resultados falsos positivos nas sorolo$\operatorname{gias}^{(12,15)}$. Uma possível correlação entre o aspecto macroscó- 
pico do soro do doador e o resultado final do teste sorológico foi descrita. No estudo, dos 550 possíveis doadores, 120 (21,8\%), foram excluídos da doação devido a testes virais positivos. Destes, 84 (70\%) possuíam soro macroscopicamente anormal, sugerindo que a análise do soro pode predizer resultados no sentido de auxiliar a avaliação dos doadores ${ }^{(16)}$.

Existem evidências clínicas e sorológicas da transmissão de hepatite $\mathrm{B}$ para alguns receptores de córneas submetidos à ceratoplastias penetrantes, cujos doadores possuíam histórico e exames laboratoriais compatíveis com a infecção viral ${ }^{(5)}$.

A utilização de testes de ácidos nucléicos para a confirmação ou não dos resultados positivos é preconizada por alguns autores $^{(12,14,17-18)}$, uma vez que estes testes realmente detectariam a existência de infecção, já que anticorpos detectados por métodos sorológicos tradicionais poderiam persistir por muito tempo após ter cessado a infecção ativa ${ }^{(18)}$. Uma vez mais, um dos fatores limitantes para uma triagem sorológica com testes de ácidos nucléicos são os custos dos mesmos.

Em um estudo de 3.228 registros de doadores, num período de 3 anos, foram observados os seguintes índices de positividade nas amostras sorológicas: $0,25 \%, 0,93 \%$ e $0,031 \%$ respectivamente para hepatites B e C e HIV ${ }^{(1)}$. A prevalência de vírus HIV foi a menor entre as três virologias associadas, fato observado também em nosso estudo.

A positividade para hepatite $\mathrm{C}$ nas amostras estudadas nesta série foi de 2,9\%, índice menor do que o encontrado por outros autores $^{(12)}$ que ao estudarem sorologias de 851 córneas (438 doadores) entre 1993 e 1997, observaram a presença de anticorpos contra vírus hepatite $\mathrm{C}$ em 29 doadores $(6,6 \%)$. Em um estudo de 2.382 doadores de córnea, 3 tiveram teste para HbsAg positivo, 6 doadores com teste positivo para hepatite C, 1 para sífilis e 1 para HIV. Trinta e seis córneas foram rejeitadas por testes inconclusivos. Entretanto, a causa mais comum de exclusão de tecidos foi decorrente das anormalidades observadas na microscopia especular (200 córneas) ${ }^{(10)}$.

Outro aspecto importante, abordado na literatura, diz respeito à soroconversão em relação à sorologia para detecção de vírus HIV ${ }^{(19)}$, relatando que pode existir a janela imunológica por 4 a 6 semanas após a contaminação, em que não se detecta anticorpos, levando a falseamento de dados.

Quando comparamos a procedência dos doadores e a positividade das amostras, observamos que os doadores procedentes do HSP apresentaram os maiores índices de positividade para hepatites $\mathrm{B}$ e $\mathrm{C}(\mathrm{p}<0,001 \mathrm{e} \mathrm{p}=0,014$ respectivamente). $\mathrm{O}$ mesmo não foi observado para o HIV. Faz-se necessário confirmar as sorologias, estudar melhor as condições da população avaliada, bem como verificar as condições e o tempo no processamento das amostras, para que obtenhamos dados mais fiéis.

Sugerimos ainda, que estudos futuros possam esclarecer se o local das punções para retirada do sangue a ser processado, poderia influenciar no resultado das sorologias, contribuindo para racionalizar os dados dos doadores de modo a não excluir córneas que poderiam ser utilizadas.

\section{CONCLUSÃO}

Este estudo confirma a validade e a importância da realização de testes sorológicos no sentido de excluir córneas com sorologias positivas ou indeterminadas para a prevenção de infecções que poderiam ser transmitidas aos eventuais receptores de córneas. Há a necessidade de serem realizados novos estudos visando uma melhor análise dos casos considerados inconclusivos, para que se evite o descarte de córneas que poderiam ser aproveitadas.

\section{ABSTRACT}

Purpose: To investigate discarded corneas due to positive serologic tests in donors from the Hospital São Paulo Eye Bank (BOHSP) during a two-year period. Methods: Retrospective study of records from cornea donors between January 2006 and December 2007. Information such as serologic test results (Hepatitis B, C, and HIV), source of corneal tissue, donor's gender and age were tested for correlation. Results: 902 corneas were processed by BOHSP; $12.9 \%$ (116) were discarded due to donor's positive test for hepatitis B, C, or HIV; $20.5 \%$ (185) were also discarded due to inconclusive result of serological tests; percentage of corneas discarded due to positive or inconclusive serological tests during this period was 33.4\% (301). Conclusion: This study confirms the importance of serological tests in order to prevent disease transmission to corneal transplant recipients. However, new tests are necessary to decrease the number of inconclusive tests and decrease the number of discarded corneas.

Keywords: Eye banks; Eye infections, viral; Cornea/microbiology; Corneal transplantation; Serology; Hepatitis C/diagnosis; Tissue donors

\section{REFERÊNCIAS}

1. Armstrong AS, Gangam N, Chipman ML, Rootman DS. The prevalence of positive hepatitis B, hepatitis C, and HIV serology in cornea donors prescreened by medical and social history in Ontario, Canada. Cornea.1997;16(5):512-6.

2. Raber IM, Friedman, HM. Hepatitis B surface antigen in corneal donors. Am J Ophthalmol. 1987;104(3):255-8.

3. Hassan SS, Wilhelmus KR. Quality assessment and microbiologic screening of donor corneas. Cornea. 2007;26(8):953-5.

4. Hassan SS, Wilhelmus KK, Dahl P, Dais GC, Roberts RT, Ross KW, Varnum BH; Medical Review Subcommittee of the Eye Bank Association of America. Infectious disease risk factors of cornea graft donors. Arch Ophthalmol. 2008;126(2):235-9. Comment in: Arch Ophthalmol. 2008;126(2):235-9.

5. Hoft RH, Pflugfelder SC, Forster RK, Ullman S, Polack FM, Schiff ER. Clinical evidence for Hepatitis B transmission resulting from corneal transplantation. Cornea.1997;16(2):132-7. Comment in: Cornea. 1997;16(2):123-4.

6. Maddox RA, Belay ED, Curns AT, Zou WQ, Nowicki S, Lembach RG, et al. Creutzfeldt-Jakob disease in recipients of corneal transplants. Cornea. 2008; 27(7):851-4.

7. Brasil. Ministério da Saúde. Agencia Nacional de Vigilância Sanitária. Sistema de Legislação em Vigilância Sanitária. Resolução RDC n 67, de 30 de setembro de 2008 Dispõe sobre o regulamento técnico para o funcionamento de bancos e tecidos oculares de origem humana. [citado 2008 Jun 23]. Disponível em: http://e-legis.anvisa.gov.br/leisref/public/showAct.php 
8. Tiabbes H. Donor screening: an overview of current regulation and practices in Europe. Transplant Proc. 1996;28(5):2950-2.

9. Adan CB, Diniz AR, Perlatto D, Hirai FE, Sato EH. [Ten years of corneal donation to the Hospital São Paulo Eye Bank: characteristics of cornea donors from 1996 to 2005]. Arq Bras Oftalmol. 2008;71(2):176-81.

10. Moyes AL, Holland EJ, Palmon FE, Dvorak JA, Doughman DJ. Tissue utilization at the Minnesota Lions' Eye Bank. Cornea. 1995;14(6):571-7.

11. Sousa LB, Chicani CF, Saud EE, Faria T, Sato EH. Perfil das doações de cornea no Banco de Olhos do Hospital São Paulo. Arq Bras Oftalmol. 1997; 60(6):608-16.

12. Cahane M, Barak A, Goller O, Avni I. The incidence of hepatitis C virus positive serological test results among cornea donors. Cell Tissue Bank. 2000;1(1):81-5.

13. Heim A, Wagner D, Rothämel T, Hartmann U, Flik J, Verhagen W. Evaluation of serological screening of cadaveric sera for donor selection for cornea transplantation. J Med Virol. 1999;58(3):291-5.

14. Patel HY, Brookes NH, Moffat L, Sherwin T, Ormonde S, Clover GM, et al. The New Zealand National Eye Bank study 1991-2003: a review of the source and management of corneal tissue. Cornea. 2005;24(5):576-82.
15. Pereira BJ, Milford EL, Kirkman RL, Quan S, Sayre KR, Johnson PJ, et al Prevalence of Hepatitis C virus RNA in organ donors positive for hepatitis $\mathrm{C}$ antibody and in the recipients of their organs. N Engl J Med. 1992; 327(13):910-5. Comment in: N Engl J Med. 1993;328(7):511-2; author reply 513. N Engl J Med. 1993;328(7):52-3. N Engl J Med. 1993;328(7):512; author reply 513 .

16. Challine D, Roudot-Thoraval F, Sabatier P, Dubernet F, Larderie P, Rigot P, et al. Serological viral testing of cadaveric cornea donors. Transplantation. 2006;82(6):788-93.

17. Laycock KA, Wright TL, Pepose JS. Lack of evidence for hepatitis C virus in cornea of seropositive cadavers. Am J Ophthalmol. 1994;117(3):401-2.

18. Center for Disease Control and Prevention (CDC). Hepatitis C virus transmission from an antibody- negative organ and tissue donor- United States 2000-2002. MMWR Morb Mort Wkly Rep. 2003;52(13):273-4, 276.

19. Pepose JS, Pardo F, Kessler JA, Kline R, Donegan E, Quinn TC. Screening cornea donors for antibodies against human immunodeficiency virus. Efficacy of ELISA testing of cadaveric sera and aqueous humor. Ophthalmology. 1987; 94(2):95-100 